I Pontifícia Universidade Católica do Rio de Janeiro (PUC-Rio),

Departamento de História, Rio de Janeiro, RJ, Brasil

larissa_correa@puc-rio.br

Larissa Rosa Corrêa'

\title{
CORPORATIVISMO E REGULAMENTAÇÃO DO TRABALHO NO BRASIL: UM DEBATE ENTRE ESPECIALISTAS BRASILEIROS E NORTE-AMERICANOS NA DÉCADA DE 1960
}

Desde o início do programa da American Federation of Labor - Congress Industrial Organizations (AFL-CIO) no Brasil, ainda na década de I940, a aplicação do modelo corporativista nas relações de trabalho esteve no centro dos debates e críticas sobre o movimento sindical do país. Para os sindicalistas da maior confederação sindical estadunidense e especialistas norte-americanos nas questões trabalhistas internacionais, o sistema corporativista, identificado com a política trabalhista de Getúlio Vargas e implantada durante a ditadura do Estado Novo (I937-I945), representava um grande obstáculo para o desenvolvimento industrial e para a implantação do sindicalismo "livre e democrático" no país.

Em I962, a AFL-CIO, com fundos da Agency for International Development (USAID) e com a colaboração das multinacionais norte-americanas, criou o Instituto Americano para o Desenvolvimento do Sindicalismo Livre (IADESIL). Além de desmobilizar as lideranças sindicais tidas como comunistas ou antiamericanas, o objetivo do IADESIL era promover a implantação das negociações coletivas diretas entre patrões e empregados e independentes do Estado, por meio da atuação de uma federação nacional de trabalho, que atuasse nos moldes da central norte-americana. Esta deveria ser apoiada e patrocinada por organizações internacionais. Dessa forma, esperava-se que as negociações diretas com os empregadores substituíssem, de modo gradativo, o já consolidado sistema corporativista de trabalho. 
$\mathrm{Na}$ visão dos sindicalistas norte-americanos, os novos dirigentes sindicais locais, treinados pelo IADESIL, deveriam ser responsáveis pela implantação do chamado "sindicalismo livre". Segundo o modelo sindical norte-americano, as novas lideranças deveriam representar apenas os problemas específicos da classe trabalhadora, focando suas ações nas negociações coletivas e nas melhorias das condições de trabalho. De acordo com a filosofia da AFL-CIO, o movimento sindical deveria permanecer independente, livre de qualquer partido ou dogma político, para que não corresse o risco de ser absorvido ou utilizado para outros fins. Salários e condições de trabalho deveriam ser determinados não pela simples vontade dos empregadores, mas por meio da negociação coletiva a ser realizada por sindicatos livres (Gordon, I963: 59). Esse pensamento foi amplamente compartilhado pelo governo estadunidense e adotado como referencial para a criação da política internacional da AFL-CIO no Brasil e em outras partes do Globo.

Neste artigo procuro analisar as diferentes visões e os debates travados por especialistas brasileiros e norte-americanos sobre o funcionamento do sistema corporativista nas relações de trabalho no Brasil ao longo da década de I960. Nesse sentido, o golpe civil-militar de I964 representa um marco divisor no direcionamento desses debates. Com base na análise das fontes locais e estadunidenses, tais como os relatórios produzidos pela embaixada norte-americana ao Departamento do Estado, busca-se compreender como os sindicalistas norte-americanos contribuíram para a construção de uma imagem negativa do corporativismo brasileiro a partir das suas ideias influenciadas pela Guerra Fria e pela luta contra o fascismo italiano. O estabelecimento e atuação da entidade sindical norte-americana IADESIL no Brasil, ao longo da década de I960, mostra-se fundamental para a estimulação dos debates acerca do sistema ideal de regulamentação do trabalho, bem como suas aplicações no país.

Inicialmente, serão analisados dois projetos que visavam implantar mudanças no sistema de regulamentação trabalhista brasileiro: o primeiro, realizado por Evaristo de Moraes Filho e, outro, por Arnaldo Süssekind, dois dos maiores especialistas na área do Direito do Trabalho no Brasil. Ambos os projetos dialogam de diferentes formas com o modelo estadunidense de regulamentação trabalhista; ambos não foram implantados devido às decisões políticas e econômicas tomadas pelo governo de Castello Branco (I964-I967), quando os militares tomaram o poder. A segunda parte do artigo apresenta os tipos ideais do contratualismo e do corporativismo, traçando reflexões gerais sobre a sua aplicação prática nos Estados Unidos e no Brasil. Com base nas análises feitas por Stanley Gacek e Tamara Lothian, dois advogados especialistas na área do Direito do Trabalho, este estudo chama a atenção para a flexibilidade do sistema corporativista e como ele poderia ser utilizado em diferentes contextos políticos. 


\section{O IADESIL NO BRASIL}

Para o governo dos Estados Unidos, a situação política no Brasil, no início dos anos I960, era perigosa e preocupante. Segundo os especialistas daquele país, descrever as condições dos trabalhadores da América Latina era o mesmo que retratar a sociedade latino-americana como um todo: "fraca, analfabeta, subnutrida, sem moradia, revoltada, cheia de ideias reformistas num mundo subdesenvolvido". E era justamente esse quadro geral de descontentamento que os norte-americanos acreditavam ser os povos dessa região uma "presa fácil" para o avanço da ideologia comunista. A classe trabalhadora, advertiam os especialistas norte-americanos, deveria ser vista como uma força revolucionária em potencial. ${ }^{\mathrm{I}}$

Para os Estados Unidos urgia, assim, a necessidade de se fazer algo nessa área, não apenas pela "ameaça de Castro". Acreditava-se ser preciso formar uma nova classe trabalhadora anticomunista capaz de reproduzir o modelo estadunidense de regulamentação trabalhista e assim facilitar o relacionamento entre empregados e empregadores estrangeiros, que visavam participar do forte período de desenvolvimento industrial, provocado em grande parte pela instalação de multinacionais norte-americanas na região. Como assinalou Cecília Azevedo, no início dos anos de I960, a política externa norte-americana voltou-se para a América Latina, buscando preservar um clima favorável para investimentos estrangeiros (Azevedo, 2008: I4I).

Nesse contexto foi criado o IADESIL. A entidade buscava atuar como um exemplo de "harmonização" de interesses entre capital e trabalho. Para o desenvolvimento de suas atividades na América Latina, o IADESIL contava com o apoio da CIA, do Departamento do Estado, dos industriais e da cúpula sindical norte-americana. A entidade se orgulhava de sua composição tripartite, agregando em seu conselho administrativo representantes de empregados e empresários. ${ }^{2}$

No caso do Brasil, durante os governos de Jânio Quadros (I96I) e João Goulart (I96I-I964), o programa teve um início tímido e bastante problemático devido à atuação crescente dos movimentos sociais populares, liderados pelos grupos de esquerda e nacionalistas, que tinham uma estreita relação com o governo federal e uma posição crítica ao programa norte-americano (Ribeiro, 2006: 89). Além disso, a relação diplomática entre o governo do Brasil e dos Estados Unidos naquela conjuntura era bastante instável e, na maioria das vezes, se desenvolvia de forma demasiadamente tensa (Loureiro, 2012: I57-I72).

Embora o sindicalismo norte-americano tenha se aproximado dos trabalhadores brasileiros de modo mais efetivo durante o regime militar, seu interesse pelo movimento sindical no país data de período anterior. Na década de I940, assombrados com o avanço do comunismo no mundo e especialmente nos países "periféricos", após a Segunda Guerra Mundial, os Estados 
Unidos decidiram implantar um programa de treinamento de liderança sindical em toda a América Latina, incluindo o Brasil (Welch, I995: 62-67). Acreditava-se ser necessário ensinar aos países vizinhos como gerenciar as relações de trabalho com o objetivo de manter a produtividade, promover a estabilidade e afastar os "agitadores comunistas".

Serafino Romualdi, representante da AFL-CIO na América Latina e anticomunista fervoroso, mostrava-se um forte crítico do corporativismo brasileiro. Segundo ele, o corporativismo era "o maior fator provocador do caos político e desastre econômico que assolava o Brasil”. Era também para ele um sistema controlador das atividades sindicais (Romualdi, I967: 39). ${ }^{3}$ Durante os anos I950, Romualdi acompanhou os eventos políticos brasileiros e realizou algumas viagens ao Brasil para travar contatos com políticos influentes e promover alianças com dirigentes sindicais. Na visão do dirigente da AFL, ${ }^{4}$ os sindicalistas brasileiros eram incrivelmente dependentes do governo federal e ainda tinham muito que aprender sobre o método das negociações coletivas.

Nesse mesmo período, Robert J. Alexander, professor da Rutgers University, ligado ao Partido Social Democrata e especialista em estudos sobre o sindicalismo latino-americano, mostrou-se preocupado com o papel controlador que o Estado exercia sob o movimento sindical brasileiro. Em um dos seus relatórios enviados para a AFL-CIO ele traçou observações sobre o forte controle do Estado em relação às atividades financeiras e administrativas dos sindicatos brasileiros, asseverando que a prática direta das negociações coletivas entre patrões e empregados, ou seja, sem a intervenção normativa da Justiça do Trabalho, ainda era muito incipiente no país. ${ }^{5}$

A atuação do IADESIL no Brasil e no restante da América Latina justificava-se à medida que os especialistas norte-americanos criavam uma imagem estereotipada sobre o sistema de regulamentação trabalhista na região. Segundo eles, o Brasil não apenas rejeitava o método da negociação coletiva como também não sabia aplicá-lo. ${ }^{6}$ Para os especialistas norte-americanos, os confrontos entre patrões e empregados intermediados por um órgão vinculado ao Estado eram inaceitáveis, assim como as relações entre os sindicalistas e autoridades políticas. Da mesma forma eram interpretados o envolvimento dos trabalhadores nas questões políticas. Os sindicalistas e especialistas do trabalho norte-americanos também reprovavam o modo como o movimento sindical brasileiro lidava com as demandas de trabalho. Para eles, os trabalhadores não sabiam separar as reivindicações trabalhistas das questões sociais, práticas que eles denominavam de "barganha política".

\section{CORPORATIVISMO: O MAL DE TODOS OS MALES?}

Na visão dos críticos e formuladores da política sindical internacional estadunidense, o sistema de regulamentação do trabalho, identificado com a ditadu- 
ra de Getúlio Vargas e com o corporativismo da Itália fascista, representava um grande obstáculo para a implantação do sindicalismo "livre e democrático" no país. Parte das críticas dos norte-americanos tinha origem nas diferenças profundas existentes entre o corporativismo e a democracia liberal, que marcavam diferentes pontos de vista sobre política e sociedade, como observou Kenneth Erickson. O individualismo altamente valorizado no liberalismo, fundamentado na proteção da liberdade individual, se opunha frontalmente à concepção corporativista. Este tinha suas bases na organização da sociedade, composta por grupos divididos de acordo com seu papel econômico e produtivo, reconhecidos pelo Estado. Erickson observou que muitos pesquisadores norte-americanos dos anos I960 e I970, impregnados pela tradição do liberalismo e do conceito de democracia liberal, entendiam que as nações em desenvolvimento deveriam seguir o modelo das democracias dos países anglo-saxões. Aos olhos desses estudiosos, a única alternativa possível ao modelo liberal seria o marxismo (Erickson, I977: 2). ${ }^{7}$

O corporativismo, tido como a terceira maior corrente do pensamento político Ocidental, influenciada por dois importantes pensadores, Aristóteles e São Tomás de Aquino, era praticamente ignorado pelos cientistas políticos norte-americanos. ${ }^{8}$ Para eles, as relações de trabalho que tinham como princípio solucionar os conflitos por meio de órgãos do Estado eram típicas dos países de cultura política latino-católica. É possível, como argumentou Erickson, que essa identificação do corporativismo com o nazifascismo tenha levado a geração de cientistas políticos norte-americanos do pós-guerra a ignorar as características corporativistas dos países com os quais eles se solidarizavam (Erickson, I977: I84). Como bem observou Clifford Welch "para muitos liberais norte-americanos, o sistema corporativista de trabalho era um pesadelo" (Welch, I995: 67).

Talvez não fosse necessariamente o caso de ignorar, como asseverou Erickson, mas talvez de interpretar o corporativismo como um sistema de características engessadas, de modo a entender que suas regras por si só inviabilizassem o que eles imaginavam constituir as bases para o desenvolvimento do verdadeiro movimento sindical. Desse modo, a ideia de que o sistema corporativista não servia aos trabalhadores latino-americanos, fosse porque impedia a cooperação efetiva entre capital e trabalho, ou porque minava as ações dos trabalhadores, cooptados e manipulados pelo sistema, era compartilhada por acadêmicos e sindicalistas norte-americanos. Estes últimos se incumbiram de ensinar aos trabalhadores latino-americanos o que acreditavam ser o sistema ideal, baseado nos problemas específicos dos trabalhadores, como os reajustes salariais e as demandas por melhorias das condições de trabalho. Estas reivindicações deveriam ser conquistadas por meio da negociação coletiva direta com o empregador e sem a interferência do Estado, livre das amarras impostas pela legislação corporativista. 
Robert Alexander, em "O ABC do sindicalismo", criticou o movimento organizado dos trabalhadores latino-americanos, alertando que as centrais (equivalentes à AFL-CIO) estavam sob o controle de um ou de outro partido político. Existia uma tendência, afirmou o autor, "por parte do movimento trabalhista, de ser um instrumento dos políticos, em vez de os sindicatos usarem um ou outro partido para os seus propósitos". A consequência direta do estreito relacionamento entre o movimento sindical e a política seria o maior controle do governo sobre as organizações dos trabalhadores. Como evidência de tal fato, Alexander observou que a maioria dos países da América Latina possuía vastos códigos trabalhistas que permitiam ao Estado interferir nos assuntos internos dos sindicatos, assim como nas ex-colônias inglesas onde as regulamentações trabalhistas coloniais da Inglaterra foram mantidas pelos governos independentes.

Para Alexander, a legislação garantia aos trabalhadores benefícios que ele julgava excessivos, pois o seu efeito acabava sendo o oposto do que os legisladores desejavam. Um caso típico apontado por ele era a lei da "estabilidade" no Brasil, adquirida após dez anos de serviços prestados à empregadora. Para evitar a lei, os patrões demitiam bons operários com receio de que eles adquirissem tal direito. Em suma, Alexander acreditava que o sistema corporativista, sobretudo a legislação social e a regulamentação dos sindicatos, aplicado "nos países subdesenvolvidos" representavam um obstáculo ao desenvolvimento do capitalismo (Alexander, I962: 201-206).

É provável que essas críticas apresentadas pelos especialistas norte-americanos tenham contribuído para consolidar uma imagem estereotipada do corporativismo, não somente veiculada entre os empregadores, mas também entre os trabalhadores, sindicalistas, intelectuais e militantes políticos de esquerda. Entre as críticas mais comuns a respeito desse sistema está a ideia, bastante difundida no meio acadêmico, de que a legislação trabalhista brasileira representava simplesmente uma cópia da Carta Del Lavoro fascista italiana, sendo a Justiça do Trabalho uma peça do sistema corporativista. ${ }^{9}$ Já os empregadores e demais setores ligados a eles reclamam do abuso dos trabalhadores por recorrerem à Justiça do Trabalho para resolver "qualquer problema". Outra crítica também bastante difundida entre intelectuais e militantes de esquerda é a de que o código de leis trabalhistas foi fruto da "outorga", ou seja, de um ato de doação, do presidente da República Getúlio Vargas, durante o período ditatorial chamado de Estado Novo, que perdurou durante os anos de I937-I 945 . $^{\text {Io }}$

No entanto, sabe-se que os trabalhadores tinham melhores condições para negociar os reajustes salariais durante o período democrático anterior ao golpe civil-militar: "embora os sindicatos fossem subordinados ao Ministério do Trabalho, seu peso político fazia com que essa subordinação fosse mais formal do que real", assinalou Fernando Lopes de Almeida. O autor identificou certa flexibilidade entre o controle do Estado e as ações dos sindicatos, como 
no caso da lei de greve $n^{\circ}$ 9.070, de 15 de março de I946, que não impediu a realização de movimentos paredistas durante todo o período de vigência da lei, revogada em ig64 (Almeida, I982: I I).

Erickson observou que a lei antigreve mostrou-se "quase inaplicável" entre os anos de I946 a I964. Evidentemente, uma frase um tanto quanto exagerada do autor. ${ }^{\text {II }}$ Mas o fato é que muitos líderes souberam usar a greve ou a ameaça de paralisação como estratégias para pressionar os empregadores e a Justiça do Trabalho (Erickson, I979: 27). Estudos mais recentes, baseados em análises sistemáticas e também em pesquisas qualitativas de processos trabalhistas contribuíram para desconstruir a ideia de que os patrões, durante as décadas de i950 e início dos anos I960, enxergavam na Justiça do Trabalho um simples aparato jurídico, criado exclusivamente para endossar as práticas de exploração da mão de obra. A CLT e a Justiça do Trabalho, mesmo sendo alvo de diversas críticas (estas feitas inclusive pelas lideranças sindicais que acionavam a Justiça) e independentemente do contexto político da época em que foram elaboradas, representavam uma ferramenta importante nas mãos da classe trabalhadora (Corrêa, 20I I; Varussa, 20I2; Souza, 20I2).

A ideia de que os sistemas de regulamentação trabalhista fortemente legislados limitavam a liberdade de negociação e, consequentemente, a autonomia dos trabalhadores, ao longo do tempo transformou-se em postulado e, como toda premissa, atravessou décadas livres de críticas mais severas, como observou Fernando Teixeira da Silva. Com base na análise exaustiva de centenas de processos de dissídios coletivos tramitados na cidade de São Paulo, nos anos de I963 até março de I964, período de forte mobilização operária e bipolarização das correntes políticas, o autor relativizou o papel intervencionista do Estado nos conflitos trabalhistas coletivos. O resultado da pesquisa feita por Silva não deixa de ser surpreendente, pois conclui que, às vésperas de os militares tomarem o poder, patrões e empregadores frequentemente evitavam encaminhar suas questões aos Tribunais. Silva chamou a atenção para as nuances inerentes aos dois modelos de regulamentação trabalhista, ignoradas por aqueles que ainda insistem na oposição binária entre os dois tipos e acreditam na incompatibilidade entre a regulamentação pública e a autonomia coletiva (Silva, 2013a).

Em seu estudo realizado com base em 485 processos de negociações coletivas, Silva constatou que $55 \%$ eram de dissídios coletivos, ou seja, os resultados foram fruto da intervenção direta normativa do tribunal trabalhista. O restante da amostra foi de processos negociados em âmbito privado tendo sido os acordos apenas encaminhados para o TRT a fim de serem homologados conforme determinação da legislação trabalhista. Como se vê, a quantidade de negociações coletivas extrajudiciais não foi pequena, indicando que o sistema de regulamentação corporativista não necessariamente excluía essa via de negociação, embora tivesse que passar pelo crivo do órgão trabalhista. Os 
dados revelam que o fortalecimento do movimento operário não levou necessariamente à realização de mais acordos diretos. Silva observou ainda que a Justiça do Trabalho desempenhou um papel mais atuante nas localidades em que o movimento operário estava mais bem organizado, enquanto nas cidades do interior do Estado de São Paulo e nas categorias com menor poder de barganha o número de contratos coletivos entre empresas e sindicatos foi maior. Tais resultados, concluiu o autor, "contrariam a hipótese de que a negociação livre e direta era o caminho lógico e natural de categorias profissionais mais bem organizadas e combativas" (Silva, 2013a: 2 I0. No entanto, suas conclusões não descartam que os órgãos trabalhistas muitas vezes poderiam minar o desenvolvimento de negociações livres. Naturalmente, não podemos deixar de reconhecer o forte papel do sistema legislado nas relações trabalhistas no Brasil. No entanto, o autor mostrou empiricamente que os acordos extrajudiciais eram uma via possível para os sindicatos de trabalhadores, tendo sido utilizada com frequência.

Ao longo do período democrático, entre I945 e I964, a Justiça do Trabalho havia conquistado certa autonomia em relação ao Estado, tendo se tornado um dos instrumentos mais importantes para a formação de uma cultura de direitos na classe trabalhadora brasileira. Esse conjunto de pesquisas recentes mostram que, em determinados casos, os trabalhadores, cientes de seus direitos, buscaram instrumentalizar o aparato jurídico, a fim de aplicar as leis reguladas pelo Estado. A experiência no campo jurídico possibilitava aos trabalhadores elaborar estratégias que lhes permitiam negociar com os patrões dentro dos parâmetros previamente definidos pela legislação. Enquanto os primeiros procuravam encontrar na CLT um espaço para garantir e reivindicar direitos, os empregadores tentavam encontrar qualquer brecha, ambiguidade ou contradição legal para impedir e, até mesmo, se esquivar dos deveres trabalhistas. Ademais, a utilização do aparato jurídico pelos trabalhadores não significou o abandono de outras estratégias de luta travadas no chão de fábrica. Trabalhadores e sindicatos haviam aprendido que não era possível lutar por uma única via; afinal, era preciso pressionar empregadores e a própria Justiça do Trabalho para obter sucesso nas negociações coletivas (Corrêa, 20I I).

A interiorização das leis e da lógica do direito pelos trabalhadores, bem como a influência da Justiça do Trabalho no cotidiano das relações de trabalho, contribuíram para a construção de uma consciência de classe, ultrapassando os limites do espaço da fábrica e das relações empregado-empregador, tendo impacto direto nas experiências do movimento operário. Conforme observou Maria Célia Paoli, a "fábrica emergiu no plano público, propondo-se, ao mesmo tempo, como uma área de controle do Estado e como um espaço civil de luta pelos direitos ao trabalho e à vida" (Paoli, I987: 69).

Essa chamada "cultura de direitos" em formação na classe trabalhadora e no movimento sindical durante o período democrático conhecido como 
"populista" ao longo das décadas de I950 e primeira metade dos anos I960, era vista pelos especialistas e sindicalistas norte-americanos como mera manipulação exercida por um líder demagógico e populista e como obstáculo para o desenvolvimento harmonioso das relações de trabalho, sendo os trabalhadores completamente dependentes das ações do Estado.

A forte influência do legado de Vargas entre os trabalhadores, mesmo após a derrubada de Goulart, chamava a atenção dos analistas norte-americanos. Em uma dessas observações, o adido trabalhista Herbert Baker registrou a cerimônia de aniversário da fundação do Sindicato dos Padeiros e de Produtos Alimentícios do Rio de Janeiro, no ano de I965. Na ocasião, o discurso de um jovem deputado da União Democrática Nacional (UDN), Raymundo Nonato da Costa Rocha, contendo elogios ao governo de Getúlio Vargas no campo da legislação trabalhista, deixou o analista estrangeiro contrariado. ${ }^{\text {I2 }}$

Em outra situação, retratada já no governo do general Ernesto Geisel (I974-I979), Baker presenciou cena semelhante ao ouvir as palavras proferidas pelo conselheiro do Instituto de Segurança Social dos Trabalhadores Comerciários, Henrique Pinto de Magalhães, durante evento realizado no Sindicato dos Operadores de Elevadores do Rio de Janeiro, discurso que o adido trabalhista definiu como "altamente dramático sobre o que Vargas fez pelos trabalhadores”, mas que conseguiu arrancar "aplausos emocionados do público". Para um funcionário do IADESIL,

O grande paradoxo é que Vargas é tido pelo movimento sindical brasileiro como um herói lendário. O seu retrato está exposto no lugar de honra em quase todas as sedes dos sindicatos. Ele é falado com reverência como o primeiro homem que fez algo pelos trabalhadores. Está claro que a "imagem de pai" criada por Vargas, tem sido cuidadosamente nutrida pelos seus sucessores. Após quase três décadas de condicionamento, é praticamente um ato reflexo dos trabalhadores e dos líderes sindicais em olhar para o governo como o responsável por resolver todos os seus problemas, que nos Estados Unidos são objetos da negociação coletiva ou dos procedimentos contratuais. Essa é a dura realidade do cenário sindical brasileiro. ${ }^{\mathrm{I}}{ }^{3}$

\section{DUAS VISÕES SOBRE O CORPORATIVISMO BRASILEIRO: AS PROPOSTAS DE EVARISTO DE MORAES FILHO E ARNALDO SÜSSEKIND}

Pouco antes da deflagração do golpe civil-militar, em I964, encontrava-se em processo de elaboração uma proposta de modificação da regulamentação do trabalho, feita pelo jurista Evaristo de Moraes Filho. A primeira etapa do projeto teve início durante a campanha eleitoral de Jânio Quadros, quando Moraes Filho havia sido convidado a orientar o candidato à Presidência da República nas questões do Direito do Trabalho. Já no governo de João Goulart, o ministro da Justiça João Mangabeira, fundador e presidente do Partido Socialista, convidou o jurista - na época, já bastante experiente e reconhecido como uma das maiores autoridades na área trabalhista - a elaborar o novo Código do 
Trabalho. A obra chegou a ser aprovada por Goulart e publicada no Diário Oficial. Em seu relato sobre o processo de elaboração do Novo Código, Moraes Filho recordou o trabalho árduo e até mesmo artesanal realizado para reunir diferentes legislações trabalhistas de todo o mundo, principalmente as que mais se aproximavam do modelo corporativista brasileiro, destacando a influência do conteúdo internacional no projeto (Morel, Gomes \& Pessanha, 2007: I 2 I).

$\mathrm{O}$ anteprojeto era uma tentativa de renovação, que visava o aperfeiçoamento e o preenchimento das lacunas existentes na legislação trabalhista, sem, no entanto, querer romper com a estrutura corporativista dos anos I930. Ao todo, a obra abrangia a regulamentação de 50 profissões, inclusive o trabalho doméstico e em domicílio. Havia também uma seção destinada à criação de Conselhos, uma espécie de comissões de fábrica. De acordo com o autor do novo Código, a "finalidade era criar a cogestão e os conselhos de empresa, integrados por empregados e empregadores, a exemplo dos que já existiam na Alemanha e na Holanda, atribuindo-lhes competência puramente social, não econômica". A eles, acrescentou, "não caberia atuar sobre a direção da empresa, mas em questões de desenvolvimento de serviço, bem-estar, relações humanas e nos casos de demissão" (Morel, Gomes \& Pessanha, 2007: I2I).

Em relação ao uso do poder normativo pela Justiça do Trabalho, desde a instauração do órgão trabalhista o jurista defendia tal instituto. Achava-o progressista e fundamental nas relações entre capital e trabalho. Entendia que ele poderia ser favorável aos empregados, especialmente nos casos em que o movimento sindical fosse considerado fraco e desorganizado. Na contramão do que pensavam os especialistas norte-americanos nas questões da regulamentação do trabalho, Moraes Filho não concordava com as visões comumente manifestadas por grupos neoliberais que consideravam o poder normativo "um ato de força, uma manifestação da prepotência corporativa que, segundo eles, caracterizou a era Vargas" e continuou: "Querem extingui-lo. Mas, não! Conforme todas as constituições em vigor, a principal função do Estado é propiciar justiça aos cidadãos, resolver conflitos de qualquer natureza, compor interesses. A Justiça do Trabalho compõe interesses" (Morel, Gomes \& Pessanha, 2007: 9I).

Moraes Filho também era um defensor da unicidade sindical que, segundo ele, era anterior ao fascismo e absolutamente necessária ao Brasil para o êxito dos trabalhadores. Desde o início de sua carreira, após ter observado que os patrões defendiam a pluralidade sindical, também apoiada por Alceu Amoroso Lima, que visava à formação de um sindicalismo católico, ele passou a argumentar a favor do sindicato único. Considerava o sindicato de empresa uma pilhéria, pois só interessava aos empregadores, servindo para dividir e dispersar a força operária (Morel, Gomes \& Pessanha, 2007: I I I). Porém, o jurista posteriormente mudou de ideia e abandonou o conceito rígido de sindicato único, reconhecido e vinculado ao Ministério do Trabalho, trocando os preceitos da Consolidação das Leis do Trabalho (CLT) pelo da Organização Internacional do 
Trabalho (OIT). Na verdade, Moraes Filho defendia a unicidade sindical desde que ela não fosse imposta pelo Estado, patrocinada e governada por ele (Moraes Filho, I978: 174). ${ }^{\text {I4 }}$

Apelando aos deveres democráticos, o jurista queria colocar o Brasil no hall de países que admitiam a livre formação de entidades sindicais de cúpula. O anteprojeto previa a constituição de quatro confederações gerais: de empregadores, de empregados, de agentes autônomos e de profissionais liberais. Os seus dirigentes deveriam ser escolhidos por eleições livres e esses não poderiam ser reeleitos. No entanto, na visão de Moraes Filho, a extinção do imposto sindical era fundamental para a existência de centrais sindicais sem vínculos com o Estado. A anulação deveria ocorrer de forma progressiva (Morel, Gomes \& Pessanha, 2007: I 23).

No tocante à redução de pessoal com base na justificativa de crise econômica, argumento bastante utilizado pelos patrões nas décadas de I950 e início de I960, Moraes Filho intencionava disciplinar essa questão. A CLT tratava a demissão coletiva de trabalhadores como ação individual na Justiça do Trabalho. Citando a experiência do sindicalismo norte-americano, o jurista criticou a ação dos empregadores que usavam a demissão quando pressionados pelos reajustes salariais, esclarecendo ainda que tal impedimento não limitava a autonomia do empregador em reduzir o seu quadro de funcionários. Tanto no assunto da redução de pessoal, em que os empregadores usavam como justificativa a crise econômica para demissão em massa, quanto no tema da estabilidade do trabalhador, Moraes Filho foi contundente em garantir a fixação do empregado em seu posto de trabalho. $\mathrm{O}$ anteprojeto mantinha o direito à estabilidade, adquirido pelo empregado após dez anos de serviços prestados à empresa. Segundo o jurista, o direito alemão e o francês mostravam-se mais regulamentaristas do que o brasileiro, sendo a política de mão de obra naqueles países muito mais rigorosa.

Em I963, a proposta do Novo Código foi publicada e uma comissão encarregada da sua revisão foi constituída (Morel, Gomes \& Pessanha, 2007: I 24). No entanto, o projeto de Evaristo de Moraes Filho não despertou grande entusiasmo nos setores ligados ao governo João Goulart, embora não se saiba a reação do movimento sindical ao projeto, tema que, aliás, merece ser investigado. Os empregadores, evidentemente, mostraram-se receosos com o novo Código. Com ampla repercussão na mídia, o projeto também chamava a atenção e gerava comentários dos analistas estrangeiros. Dos norte-americanos, Moraes Filho contou ter recebido um ofício do Ministério das Relações Exteriores, informando que o adido trabalhista da Embaixada americana pretendia intervir em vários aspectos do projeto. Eles eram contra a estabilidade, tão enfatizada no Código de Moraes Filho, e a manutenção da Lei da Nacionalização do Trabalho, que exigia das empresas a contratação de dois terços de trabalhadores brasileiros. ${ }^{15}$ Mas a proposta manteve-se inalterada (Morel, Gomes \& Pessanha, 2007: I25). 
Do convite de elaboração do Código até a publicação da obra, Moraes Filho presenciou a efervescência dos movimentos políticos que levaram à derrocada de João Goulart e à instalação da ditadura militar. Ainda incumbido de dar continuidade ao projeto, Moraes Filho procurava invocar "o espírito democrático e o comprometimento do novo presidente da República com a liberdade sindical" (Última Hora, I7 de julho de I964, p. 3). Em meados de I964, a Embaixada americana apurou os rumores de que os ministros da Fazenda e do Planejamento, Octávio Bulhões e Roberto Campos, assim como o Conselho de Segurança Nacional, estavam contra o projeto. ${ }^{16} \mathrm{~A}$ obra sequer foi enviada ao Congresso. Composto por dois volumes, o anteprojeto de Moraes Filho foi finalizado em I 963 e a revisão publicada somente dois anos depois.

Com os militares no poder, a AFL-CIO e os adeptos do chamado "sindicalismo livre" no Brasil ansiavam por reformas na legislação trabalhista, visando estimular a negociação coletiva direta entre empregados e patrões. Paralelamente à elaboração de uma nova política trabalhista idealizada pelos ministros da Fazenda e do Planejamento, o ministro do Trabalho, Arnaldo Süssekind, na época um entusiasta do modelo trabalhista norte-americano, enviou, no dia 29 de maio de I965, um anteprojeto de lei intitulado "Convenções Coletivas de Trabalho e Contrato Coletivo de Trabalho" para apreciação do Congresso Nacional.

A proposta intensificou os debates sobre a implantação do modelo contratualista no Brasil. O conteúdo do documento recebeu elogios do adido trabalhista Harold Shapiro. Segundo ele, o projeto previa a negociação de boa-fé por parte dos empregadores e permitiria aos trabalhadores o recurso da greve como força de negociação, embora a proposta apresentasse algumas ambiguidades terminológicas e restrições, como o mínimo de dois anos de vigência do contrato. Todavia, se aprovada - avaliou -, a lei poderia representar "um grande passo em direção ao sindicalismo organizado". ${ }^{\text {I7 }}$

Para Süssekind, embora o Decreto $\mathrm{n}^{\circ}$ 2I.76I, de 23 de agosto de I932, tivesse disciplinado a prática das convenções coletivas de trabalho, a sua aplicação era quase inexistente. ${ }^{18}$ Os motivos, assim ele explicou, estavam no "caráter rígido das normas que lhe dão disciplina e ao sentido, entre nós, dominante, de que todas as soluções devem emanar do Estado" (Santos, I967: s/p, Anexo). Nesse sentido, o projeto de lei visava proporcionar maior flexibilidade às normas existentes na CLT, a fim de estimular a celebração das convenções coletivas de trabalho, julgadas "o melhor e mais adequado instrumento de autocomposição dos interesses profissionais" (Santos, I967: s/p, Anexo). Além disso, acreditava-se que tal prática contribuiria para desafogar a Justiça do Trabalho, tornando-a mais ágil e menos intervencionista. Para o autor do anteprojeto, a rigidez e a esquematização exagerada do código do trabalho não poderiam mais acompanhar o ritmo do progresso em desenvolvimento no país. ${ }^{19}$

De acordo com o projeto de Süssekind, a recusa dos empregadores em negociar poderia levar o caso ao Ministério do Trabalho, e se ainda assim não 
fosse travada negociação, os trabalhadores poderiam declarar greve, forçando o diálogo com o empregador. Porém, a paralisação seria considerada ilegal caso tivesse a finalidade de alterar, no todo ou em parte, a convenção coletiva (realizada entre sindicatos) ou o acordo coletivo (entre empresas e sindicatos). A Justiça do Trabalho deveria ser acionada somente nos casos de controvérsias resultantes da aplicação do contrato. $O$ anteprojeto também permitia a constituição e o funcionamento de concessões mistas de consulta e colaboração nas empresas. Além disso, não estabelecia restrições aos pontos que poderiam ser negociados. Tudo que resultasse de acordo, desde que o objeto fosse lícito, teria condições de ser contratualmente incluído na negociação coletiva.

No entanto, contrariando as expectativas dos norte-americanos, paralelamente à submissão do anteprojeto de lei para a reformulação das negociações coletivas, tramitava no Congresso o projeto "7-65", proposto pelo governo, que versava sobre a política dos reajustes salariais. A fim de recuperar a estabilidade do plano econômico-financeiro do governo, o projeto abarcava o setor privado, com restrições às esferas públicas e às autarquias. A proposta considerava ainda a capacidade das empresas de pagar o aumento do custo de trabalho, assim como a necessidade de corrigir as iniquidades dos níveis salariais entre os setores por meio do arrocho salarial. A Justiça do Trabalho deveria aderir às normas de reajuste salarial nas negociações dos dissídios coletivos, passando a ter poder normativo limitado. Com isso, os reajustamentos salariais deixariam de ser alvo de disputas na Justiça do Trabalho e passariam ao controle do Poder Executivo. ${ }^{20}$

Assim, em meados de 1965 encontravam-se em apreciação três projetos que previam mudanças na legislação trabalhista. O primeiro, proposto por Evaristo de Moraes Filho, foi rapidamente engavetado pelos militares. Os dois últimos, gestados logo após o golpe, tinham origens distintas e extremamente conflitantes. O "7-65", que contava com 57 emendas desde o projeto original, teve grande repercussão tanto no Congresso quanto no movimento sindical em geral. A aprovação do projeto, consequentemente, descartava a proposta apresentada por Süssekind de estimular as negociações coletivas livres, apesar dos esforços da entidade sindical norte-americana IADESIL e da estreita relação entre o governo estadunidense e a administração de Castello Branco. ${ }^{2 \mathrm{I}}$

O "7-65" passou a vigorar por meio da Lei $n^{\circ} 4.725$, assinada em I3 de julho de i 965 . Além da nova lei, os trabalhadores foram afetados pelo forte controle das atividades sindicais, pela limitação do direito de greve e o arrocho salarial. De outro lado, tais medidas minaram os planos dos sindicalistas norte-americanos de instituir um novo modo de "harmonização" das relações capital-trabalho. A decretação da Lei ${ }^{\circ} 4.725$ deixou evidente a opção do governo de Castello Branco pela manutenção do sistema corporativista, incluindo a Justiça do Trabalho. Ao invés de extingui-la, o regime ditatorial decidiu man- 
ter a instituição e depurá-la, afastando aqueles profissionais que não se enquadravam na ideologia autoritária (Corrêa, 20I3). O arrocho salarial e a interferência direta nos dissídios coletivos julgados na Justiça do Trabalho, aliado ao forte aparato repressivo utilizado para controlar as ações políticas dos sindicatos, impactaram diretamente na qualidade de vida dos trabalhadores e no movimento sindical organizado. A nova política salarial provocou a perda real dos salários e privilegiou os setores com renda elevada, responsáveis pela maior fatia do mercado consumidor de bens duráveis (Almeida, I982: I7-I9).

O projeto de negociação coletiva foi retirado do Congresso em meados de junho de i965. Sem dar explicações públicas, o governo alegou apenas a incompatibilidade entre os dois projetos. A Embaixada americana apontou para a dificuldade de realização das negociações coletivas no Brasil sem um sólido equilíbrio de poder entre os donos do capital e da mão de obra. Na visão do adido trabalhista Herbert Baker, os industriais brasileiros não estavam dispostos a fazer grandes mudanças no relacionamento com seus subordinados. ${ }^{22}$ Segundo Arnaldo Süssekind, o Congresso Nacional teria aprovado a "toque de caixa" a Lei $n^{\circ} 4.725$, que se tornaria conhecida como a "lei do arrocho". A aprovação da lei ocorreu durante a sua participação na conferência da OIT, realizada em Genebra, fato que teria ameaçado a permanência dele no Ministério do Trabalho, conforme o seu depoimento (Gomes; Pessanha \& Morel: 2004: I 35).

Entretanto, é possível que o governo de Castello Branco tenha incorporado alguns pontos do projeto de lei de negociação coletiva no Decreto-Lei $\mathrm{n}^{\circ}$ 229, de 28 de fevereiro de I967, que alterou o título VI da CLT sobre as convenções coletivas de trabalho. Diferentemente do decreto de I932, o artigo 6 I6 dava nova redação aos acordos coletivos. Uma vez que uma das partes interes sadas, representantes de patrões ou empregados, sinalizasse a intenção de entabular negociação coletiva direta, ou seja, sem a interferência da Justiça do Trabalho, a outra parte não poderia se recusar à negociação. Ou seja, a convocação para negociação coletiva passou a ser compulsória nos casos em que uma das partes optasse por negociar diretamente. Somente após malogradas as tentativas de entendimentos é que o dissídio coletivo deveria ser instaurado.

$\mathrm{Na}$ versão original do projeto submetido por Süssekind estavam previstas sanções aos empresários que se recusassem a negociar e a possibilidade do direito de greve, dois princípios fundamentais para o exercício de pressão dos trabalhadores. Contudo, o decreto introduziu um artigo (623) que para muitos tornava nula a prática do acordo coletivo: considerava nulo qualquer acordo que, direta ou indiretamente, contrariasse as normas estabelecidas pela política econômico-financeira do governo ou a política salarial vigente. Com isso, os sindicatos de trabalhadores eram desestimulados a travar a negociação coletiva direta com o empregador, uma vez que o reajuste salarial poderia ser obtido por meio de dissídio coletivo, de forma mais ágil - lembrando que, normalmente, o patrão se recusava a negociar com os dirigentes, avaliou Süssekind. ${ }^{23}$ 


\section{ENTRE O TIPO IDEAL E A PRÁTICA DOS SISTEMAS CORPORATIVISTA E CONTRATUALISTA}

Diferentemente do sistema de regulamentação trabalhista brasileiro, nos Estados Unidos o modelo contratualista permite que os empregados se organizem como queiram, podendo formar, participar ou apoiar organizações de trabalho. Podem ainda negociar coletivamente de forma direta com seus representantes escolhidos e participar de outras atividades ou de diferentes associações. Eles também possuem o direito de se absterem de todas essas atividades, conforme determinação da Seção 8 da National Labor Relations Act (NLRA). Em tese, o governo não pode patrocinar, nem participar diretamente do processo de formação dos sindicatos, ele apenas garante o direito de o trabalhador se organizar e reconhece os sindicatos como agentes representantes dos trabalhadores. Em outras palavras, o Estado deve atuar como um expectador das relações trabalhistas (Gacek, I994).

Outra característica essencial do modelo contratualista é a sindicalização plural, pois não há nenhuma determinação prévia por parte do Estado em relação à escolha dos grupos representativos de trabalhadores. Desse modo, eles podem se organizar em diferentes níveis, seja por fábrica, empresa ou ramo de atividade. O caráter voluntarista também é marcante nas relações contratuais (Gacek, I994: I 2). ${ }^{24}$ Salários e condições de trabalho figuram como questões individuais, funcionam de forma independente e estão sujeitas às regras do direito privado. No entanto, a arbitragem também de caráter privado é fundamental para o andamento das negociações. Por fim, a última característica mais importante do contratualismo estadunidense é a separação entre a estrutura sindical e o sistema de bem-estar social. Os sindicatos não devem ter nenhuma relação com os serviços sociais ou benefícios provenientes do Estado, o que não significa que eles não possam exercer poder de pressão em relação a essas questões (Lothian, I986: I003-1004).

Tamara Lothian, advogada e especialista na área do Direito do Trabalho norte-americano, traçou comparações entre o corporativismo e o contratualismo, bem como os possíveis efeitos da aplicação desses dois sistemas no processo de politização e militância da classe trabalhadora no Brasil e nos Estados Unidos. Para a autora, os dois sistemas podem influenciar a militância sindical de maneiras muito diferentes. Suas ideias são bastante inspiradoras para pensarmos na permanência do modelo legislado no Brasil durante o regime ditatorial. Assim como Erickson, Lothian apontou para o fato de o modelo corporativista geralmente ser identificado com os regimes autoritários de direita, servindo exclusivamente como um instrumento para repressão e controle do movimento sindical. No entanto, a autora observou que em muitos países onde o sistema corporativista foi adotado, os movimentos sindicais se tornaram mais fortes, independentes e politizados, graças ao desenvolvimento de uma 
militância política que soube utilizar o aparato corporativista. Nesse sentido, a autora atenta para a importância em identificar os momentos históricos em que o corporativismo atuou como um instrumento de controle e quando passou a viabilizar a militância política.

Usando como exemplo o período do "novo sindicalismo", surgido no final da década de I970, Lothian observou que o corporativismo pode favorecer os extremos do movimento sindical, levando-o da manipulação e apatia à politização. Já o contratualismo ou o voluntarismo encorajaria um estilo de militância moderada, mais voltada às questões econômicas. Tais argumentos desconstroem a ideia bastante difundida entre os especialistas do Direito do Trabalho, como veremos nas ideias de Stanley Gacek, e críticos ortodoxos do corporativismo, entre eles os especialistas norte-americanos do período da Guerra Fria, conforme abordado inicialmente, de que as relações trabalhistas independentes, baseadas no âmbito individual e de caráter privado, seriam mais eficientes e democráticas. Nesse sentido, embora o "novo sindicalismo" não seja objeto de análise neste estudo, é importante apontar para uma contradição do movimento. Se por um lado, o "novo sindicalismo" emergiu à margem do Estado, atuando por meio das comissões de fábrica e em oposição à estrutura sindical corporativista, os trabalhadores militantes não deixaram de atuar por dentro das entidades oficiais, disputando eleições e utilizando a estrutura dos sindicatos, quando possível, ao mesmo tempo em que se organizavam nos locais de trabalho. ${ }^{25}$

Uma vez apreendido que o corporativismo não atua como um corpo monolítico e que suas leis podem ser utilizadas de forma pragmática por patrões e empregados, é possível pensar que o sistema corporativista serve tanto como um instrumento de controle e repressão como pode contribuir para politizar o movimento sindical. ${ }^{26}$ Embora Lothian afirme que a questão-chave para a promoção do controle ou da politização dos trabalhadores esteja na fraqueza da vontade política [dos trabalhadores] e na autoridade efetiva da parte do regime autoritário, acredito que a definição do uso do sistema corporativista encontra-se na relação do Estado com os representantes dos trabalhadores e do capital e no papel que cada grupo exerce em conjunturas políticas e econômicas específicas (Lothian, I986: I004).

No caso do Brasil, Lothian observou que, em diferentes contextos históricos, a experiência dos trabalhadores com o corporativismo foi bastante diversa, tendo sido alterada profundamente durante os períodos mais autoritários e democráticos. Reconhecida certa flexibilidade do sistema corporativista, a autora argumentou que sua exclusão não se torna necessária, sendo possível mantê-lo, desde que fossem feitas alterações que viabilizem a mobilização dos trabalhadores. Nesse sentido, o projeto do novo Código do Trabalho idealizado por Evaristo de Moraes Filho é bastante representativo na tentativa de amainar os instrumentos de controle das ações coletivas dos trabalhadores. Em casos de 
regime de exceção, Lothian observou que a repressão ocorre por uma combinação de fatores políticos, sendo o sistema corporativista um desses componentes.

Já Stanley Gacek, advogado norte-americano especializado nas relações sindicais latino-americanas, impactado pela efervescência política e sindical que ele testemunhou na região do $A B C$ de São Paulo no final dos anos I970 e início da década de I980, questionou alguns argumentos fundamentais da tese de Lothian. Parte das críticas feitas à autora encontra-se na própria abstração de determinados conceitos e ideias que, para Gacek, estariam distanciados das diferentes experiências políticas vivenciadas pelos trabalhadores norte-americanos e brasileiros (Gacek, I994: I8). ${ }^{27} \mathrm{O}$ autor rejeitou a ideia de que o sistema contratualista teria contribuído para o desenvolvimento de um movimento sindical norte-americano mais economicista e menos politizado, pejorativamente caracterizado como "sindicalismo de negócios", do qual a AFL-CIO seria o grande símbolo. Para ele, tais críticas vindas da esquerda norte-americana soam como uma caricatura distorcida do mundo do trabalho estadunidense e sua história, embora ele tenha reconhecido que os sindicatos dos Estados Unidos estavam em declínio nas últimas décadas, com baixo índice de organização e pouca influência política. Para Gacek, a militância operária que atua dentro dos princípios do sistema corporativista pode ser altamente anticorporativista e pró-contratualista, a exemplo do que ocorreu no "novo sindicalismo" (Gacek, I 994: I4).

O advogado norte-americano chamou a atenção para as diferenças entre o tipo ideal de cada sistema e sua aplicação na prática. O autor expõe uma série de contradições criadas pelo sistema trabalhista nos Estados Unidos, assim como as tensões geradas pelo papel atribuído ao Estado ao tentar conciliar a natureza puramente privada do contrato com determinados interesses públicos. Nesse sentido, o tipo ideal de contratualismo passa a ser subvertido pela prática jurídica. O contratualismo de âmbito privado não evita que o movimento sindical esbarre numa série de empecilhos legais que limitam sua soberania por meio do processo de reconhecimento como representante legal de determinado grupo de trabalhadores, restrições à greve, aos piquetes e atividades de boicote, entre outros (Gacek, I994: 44).

Independente de qual sistema seria o mais eficiente ou quais seriam as vantagens e desvantagens de cada um, ambos os autores contribuem para desconstruir certas ideias que de tão repetidas transformaram-se em premissas inquestionáveis nas historiografias nacional e internacional. Fernando Teixeira da Silva, ao analisar o papel do poder normativo exercido pela Justiça do Trabalho no Brasil, enfatizou os limites do Direito do Trabalho no modelo legislado em comparação com o contratual. Em suas palavras,

O Direito do Trabalho conferiu caráter público as relações sociais desenvolvidas na esfera privada, na contramão do contratualismo liberal ortodoxo, baseado na ficção jurídica da autonomia das vontades individuais. No lugar de direitos e de- 
veres definidos individualmente, segundo as regras do direito subjetivo, empregadores e empregados assentam normas coletivas de regulação de salários e condições de trabalho enquanto sujeitos de direito. O Direito do Trabalho, portanto, reconhece o trabalhador como parte integrante de um coletivo dotado de estatuto social que ultrapassa a dimensão individual do contrato de trabalho (Silva, 2013b: I2).

De modo geral, percebe-se que tanto o encaminhamento do dissídio coletivo à Justiça do Trabalho para julgar a pauta de reivindicações coletivas dos trabalhadores de uma determinada categoria, quanto a realização de um acordo coletivo feito diretamente com os patrões eram ações calculadas e seus ganhos ou perdas para os trabalhadores dependiam de uma série de outros fatores. O sucesso das reivindicações dependia fundamentalmente da força do setor produtivo, ou seja, de seu poder de barganha, bem como da organização do movimento sindical em uma conjuntura política específica.

\section{CONSIDERAÇÕES FINAIS}

Neste artigo buscou-se apresentar diversas visões sobre os modelos de regulamentação trabalhista - o corporativista e o contratualista - expondo as disputas ideológicas e jurídicas em torno desses dois sistemas. A atuação do sindicalismo norte-americano no Brasil, a partir do pós-guerra, mostrou-se importante para a construção de uma estigmatização do corporativismo brasileiro. Vimos que a entidade sindical estadunidense IADESIL, ao longo da década de I960, procurou influenciar e pautar a política trabalhista brasileira visando a implantação do chamado "sindicalismo livre e democrático". Porém, os militares e civis no poder, a partir de I964, ao reelaborar a política trabalhista e adaptá-la ao regime autoritário, fizeram uma opção clara pela manutenção do corporativismo varguista.

Ao longo da segunda metade do século XX, o sistema se transformou em sinônimo de autoritarismo, de atraso, um dos símbolos do nosso eterno capitalismo tardio. Não se trata aqui obviamente de elaborar uma defesa do corporativismo, mas de apontar para o caráter flexível desse sistema (assim como do contratualismo norte-americano) e para os seus possíveis e diferentes significados e reapropriações feitas pelos trabalhadores. Da mesma forma, procurei evidenciar os interesses e os embates político-ideológicos em torno das críticas e alterações propostas por diferentes especialistas na área do trabalho e do Direito do Trabalho.

Ao analisar o projeto no novo Código de Trabalho submetido pelo jurista Evaristo de Moraes Filho, percebe-se que havia um esforço no período que precedeu o golpe de Estado em flexibilizar o sistema corporativista de forma a deixá-lo mais progressista e democrático para os trabalhadores. Tais mudanças, no entanto, não pretendiam alterar as bases da legislação trabalhista, sendo a manutenção de alguns institutos jurídicos, como a unicidade sindical, 
defendida pelo jurista. A derrubada de Goulart representou uma grande oportunidade para o sindicalismo norte-americano intervir de modo mais efetivo na elaboração de uma nova política trabalhista. Mas, como vimos, o direito de greve e as negociações coletivas independentes, dois pilares do modelo contratualista, foram inviabilizados pelo governo Castello Branco. Este, optou por manter o sistema corporativista e depurá-lo para atuar como instrumento de controle e repressão ao movimento sindical e aos interesses dos trabalhadores.

As diferenciações entre o modelo ideal e a prática do sistema de regulamentação trabalhista apontados nas reflexões apresentadas pelos dois advogados trabalhistas norte-americanos, Tamara Lothian e Stanley Gacek, contribuem para relativizar as críticas em relação aos dois sistemas, chamando a atenção para o fato de que o corporativismo e o contratualismo não devem ser analisados de modo isolado. Nesse sentido, o artigo assevera a necessidade de analisar os sistemas de regulamentação trabalhista a partir da combinação de outros fatores, como as possibilidades de organização da classe trabalhadora e do regime político em que esses sistemas atuam ou se desenvolveram historicamente. Dessa forma, este estudo buscou contribuir para os debates historiográficos que questionam os aspectos monolíticos e estereotipados do corporativismo brasileiro.

Recebido em 29/oI/20I5 | Aprovado em 05/05/20I5

Larissa Rosa Corrêa é professora assistente do Departamento de História da PUC-Rio. O presente artigo baseia-se em pesquisa que resultou em sua tese de doutorado intitulada "Disseram que voltei americanizado": relações sindicais Brasil-Estados Unidos durante a ditadura civil-militar, de 20I3, que será publicada pela editora da Unicamp (no prelo). A autora desenvolve estudos na área de História Social do Trabalho, com foco na análise comparada sobre o sindicalismo latino-americano no período das ditaduras militares ocorridas na Guerra Fria. Ela é autora do livro A tessitura dos direitos: patrões e empregados na Justiça do Trabalho (I953-I964) (20II). 


\section{NOTAS}

I "Survey of the Alliance for Progress - Labor Policies and programs", documento preparado pelo Subcommittee on American Republics Affairs and Committee on Foreign Relations, United States Senate, de i5 de junho de 1968. Trata-se de uma pesquisa realizada por Robert H. Dockery, que teve como base entrevistas feitas com sindicalistas norte-americanos e funcionários da Embaixada dos Estados Unidos no Brasil e do governo estadunidense.

2 Cerca de 60 grupos empresariais contribuíram para o orçamento do IADESIL nos seus anos iniciais.

3 Serafino Romualdi, um imigrante italiano estabelecido nos Estados Unidos desde a década de I920, era opositor do regime fascista e, membro da AFL, estabeleceu os primeiros contatos com o Brasil, durante uma visita realizada ao país no ano de I945. Fez oposição ao regime fascista italiano e por isso teria imigrado para os Estados Unidos. No mesmo ano, ele se filiou à AFL e ficou responsável pelo estabelecimento dos contatos com os países latino-americanos, tornando-se, mais tarde, o representante da AFL na América Latina.

4 A fusão entre as centrais sindicais AFL e CIO ocorreu em I955.

5 Relatório escrito por Robert J. Alexander, de i3 de maio de I956. Coleção Serafino Romualdi, $n^{\circ}$ 5459, Kheel Center, Cornell University.

6 Para uma análise sobre a prática da negociação coletiva no Brasil dentro dos moldes estabelecidos pela legislação trabalhista brasileira, tendo o sistema contratualista como ponto de comparação, ver Silva (2013).

7 A versão em português do livro de Kenneth Erickson apresenta uma análise resumida sobre o conceito teórico de corporativismo e seu uso na historiografia norte-americana, ver Erickson (1979).

8 Porém, havia exceções, como o próprio Erickson apontou: Malloy (I977), Souza (I975), Stepan (I978), Wiarda (I974), Schmitter (I974).

9 Pesquisas recentes têm questionado fortemente a afirmação de que Consolidação das Leis Trabalhistas (CLT) era 
simplesmente uma cópia da Carta fascista, tendo tido influência dos modelos implantados por outros países, como os Conseils de Proud' Hommes, na França, a Constituição alemã de Weimar, além da encíclica Rerum Novarum, de I89I. Ver Silva (2010).

Io Para uma crítica sobre a interpretação da outorga dos direitos trabalhistas regulamentados por Getúlio Vargas, ver Gomes (I988).

I I Sobre o uso do direito de greve pelos trabalhadores no pré-I964, ver Silva (2013a). O autor analisou os debates no meio jurídico em torno do Decreto-Lei 9.070, de I946, com foco nas ações dos tribunais trabalhistas para disciplinarização do direito de greve. Segundo ele, a lei impunha aos trabalhadores e sindicatos sérios limites às ações grevistas. Segundo o autor, os juízes, com frequência, acolhiam os argumentos dos empregadores que buscavam punições aos empregados grevistas entrando com ações individuais na Justiça do Trabalho para efetuar as demissões.

I 2 Relatório da Embaixada dos Estados Unidos no Brasil para o Departamento do Estado, de 26 de maio de I965. NARA II, General Records of the Department of State (GRDS), RG 59, Central Foreign Policy Files (CFPF), box I 28I.

I3 Memorando para George Phillips, escrito por Angel Verdu em 9 de julho de 1975. George Meany Archive, RG 038, Office of the President, pasta 68/25 - Brazil, I96I-I975 \& I979.

I4 Moraes Filho entendia que o sindicato único não deveria ser obrigatório, ou seja, o processo de sindicalização deveria ser de livre escolha do trabalhador. O Estado poderia fixar um sindicato para cada profissão, porém sem interferir nos assuntos internos da organização. O autor defendia a existência do sindicato único para cada atividade ou profissão, assim como a atuação das confederações gerais de cúpula, "sem divisionismos ideológicos, políticos ou confessionais".

I5 Tratava-se da lei $\mathrm{n}^{\circ}$ 20.29I, de I93I, que visava garantir a mão de obra brasileira e reservava no máximo I/3 de operários estrangeiros nos quadros das empresas.

I6 Relatório enviado pela Embaixada dos Estados Unidos no Brasil ao Departamento do Estado, de i 8 de novembro de 
I964, escrito por Herbert W. Baker. NARA II, General Records of the Department of State (GRDS), RG 59, Central Foreign Policy Files (CFPF), box I 28I.

I7 Relatório da Embaixada dos Estados Unidos no Brasil ao Departamento do Estado, de 29 de junho de I965, escrito pelo adido trabalhista Harold Shapiro. NARA II, General Records of the Department of State (GRDS), RG 59, Central Foreign Policy Files (CFPF), box I 282.

I8 De acordo com o decreto $\mathrm{n}^{\circ} 2 \mathrm{I} .76 \mathrm{I}$, de 23 de agosto de I932, artigo $\mathrm{I}^{\circ}$, os sindicatos e federações sindicais ou associações de empregadores ou de empregados só poderiam "celebrar convenções coletivas de trabalho quando o fizerem por expressa disposição dos seus estatutos ou por deliberação de assembleia geral especialmente convocada para esse fim, dependendo a validade dos ajustes, num e noutro caso, de ratificação, em outra assembleia, por maioria de dois terços de associados, ou terceira convocação, nos termos dos estatutos". Conforme previsto no decreto, os acordos poderiam ser suspensos temporariamente ou definitivamente, caso as Juntas de Conciliação e Julgamento julgassem necessário.

I9 Anteprojeto de lei sobre Convenções Coletivas de Trabalho e Contrato Coletivo de Trabalho, anexado no livro de Santos (I967).

20 Projeto de Lei $n^{\circ}$ 7, de I965. Arquivo da Câmara dos Deputados, Brasília, DF.

2 I O projeto de lei de negociação coletiva, submetido por Arnaldo Süssekind, não foi encontrado no arquivo da Câmara dos Deputados.

22 Relatório da Embaixada dos Estados Unidos no Brasil para o Departamento do Estado sobre o período de julho a dezembro de I965, escrito em 2 I de janeiro de I966, pelo Labor Attaché Herbert W. Baker. NARA II, LAB 3-2 BRAZ box I 282 .

23 Relatório final da CPI sobre as entidades sindicais estrangeiras no Brasil de I970, p. 37, terceira coluna. Arquivo da Câmara dos Deputados, Brasília, DF.

24 Segundo Stanley Gacek, tanto ele quanto Tamara Lothian utilizam o conceito de voluntarismo no sentido de que o aparato judicial não determina os termos do contrato cole- 
tivo, prevalecendo a liberdade sindical, sem a interferência do Estado e o uso máximo da pressão econômica não violenta por meio do direito de greve. Voluntarismo, porém, que não impede o Estado de estabelecer garantias mínimas para salários e benefícios, diferentemente do conceito de voluntarismo utilizado por Samuel Gompers e outros líderes da AFL, que interpretavam qualquer regulação do Estado na economia como antissindical.

25 As oposições sindicais, tais como a dos metalúrgicos e químicos de São Paulo, por exemplo, não deixaram de disputar eleições para compor a diretoria dos sindicatos dominados pelos chamados "pelegos". Ver Batistoni (2010), Corrêa, Macedo, Costa \& Ladosky (20I3). Para uma revisão da literatura sobre o "novo sindicalismo", ver Véras \& Ladosky (20I4).

26 O conceito de corporativismo abordado neste estudo remete ao período dos anos 1930 até a primeira metade dos anos I970. Embora ciente da importância em analisar o tema à luz dos debates que tratam do conceito de neocorporativismo nos moldes do modelo europeu, mais precisamente aplicado pelos partidos social-democratas, esse estudo debruça-se apenas nos debates entre o modelo brasileiro e norte-americano referente àquele período. Há uma extensa literatura nacional e internacional sobre os significados políticos do termo neocorporativista, voltados principalmente para as análises das relações trabalhistas a partir da década de I980. Sobre o Brasil, ver Noronha (2000), Arbix (1995), Cardoso (1999).

27 Uma delas é a dicotomia que Lothian faz entre a militância "política" e "economicista", bem como a ideia abstrata de uma definição sobre militância sindical. Gacek atentou para o fato de que, geralmente, as lutas sindicais apontam para a convergência desses dois tipos, sendo, que na prática, esses elementos tornam-se indissociáveis.

\section{REFERÊNCIAS BIBLIOGRÁFICAS}

Alexander, Robert. (I962). O ABC do desenvolvimento econômico. Rio de Janeiro: Fundo de Cultura.

Almeida, Fernando Lopes. (I982). Política salarial, emprego e sindicalismo, I964-I98I. Petrópolis: Vozes. 
Azevedo, Cecília. (2008). Em nome da América. Os Corpos de Paz no Brasil. São Paulo: Alameda.

Batistoni, Maria Rosângela. (20I0). Confronto operário. A Oposição Sindical Metalúrgica nas greves e nas comissões de fábrica de São Paulo (1978- I980). São Paulo: Núcleo Piratininga de Comunicação.

Corrêa, Larissa Rosa. (20I I). A tessitura dos direitos: patrões e empregados na Justiça do Trabalho (1953-64). São Paulo: Fapesp/ LTr.

Corrêa, Larissa et al. (orgs.). (2013). "A cobra vai fumar": a vitória da oposição sindical dos Químicos e Plásticos. In: Corrêa, Larissa et al. (orgs.). Químicos de São Paulo: 80 anos de lutas de conquistas (1933-2013). São Paulo: Sindicato dos Químicos e Plásticos de São Paulo e Região, p. 7I-Ior.

Erickson, Kenneth P. (1979). Sindicalismo no processo político no Brasil. São Paulo: Brasiliense.

Erickson, Kenneth P. (I977). The Brazilian corporative state and working-class politics. Berkeley/Los Angeles: University of California Press.

Gacek, Stanley A. (I994). Sistemas de relações de trabalho. Exame dos modelos Brasil e Estados Unidos. São Paulo: LTr.

Gomes, Angela de Castro; Pessanha, Elina G. da Fonte \& Morel, Regina de Moraes. (2004). Arnaldo Süssekind - um construtor do Direito do Trabalho. Rio de Janeiro/São Paulo/ Recife: Renovar.

Gordon, Lincoln. (1963). A New Deal for Latin America. Cambridge, MA: Harvard University Press.

Loureiro, Felipe. (2012). Empresários, trabalhadores e grupos de interesse: a política econômica nos governos Jânio Quadros e João Goulart (I96I-I964). Tese de Doutorado. São Paulo, FFLCH-USP.

Lothian, Tamara. (I986). The political consequences of labor law regimes: the contractualist and corporatist models compared. Cardozo Law Review, vol. 7, $\mathrm{n}^{\circ} 4$, p. Iоo II073.

Moraes Filho, Evaristo de. (I978). O problema do sindicato único no Brasil. São Paulo: Alfa-Omega.

Moraes Filho, Evaristo de. (1963). Anteprojeto de Código do Trabalho. Rio de Janeiro: Imprensa Nacional. 
Morel, Regina Lúcia de Moraes; Gomes, Angela de Castro \& Pessanha, Elina Gonçalves da Fonte (orgs.). (2007). Sem medo da utopia: Evaristo de Moraes Filho, arquiteto da sociologia e do direito do trabalho no Brasil. São Paulo: LTr.

Paoli, Maria Célia. (I987). "Os trabalhadores urbanos na fala dos outros”. In: Leite Lopes, José S. (org). Identidade e cultura operária. Rio de Janeiro: UERJ/Museu Nacional/Marco Zero, p. 53-Ior.

Ribeiro, Ricardo Alaggio. (2006). A Aliança para o Progresso $e$ as relações Brasil-Estados Unidos. Tese de doutorado. Programa de Pós-Graduação em Ciência Política/IFCH-Unicamp.

Santos, Reinaldo. (I967). Trabalho, salários e sindicatos nos Estados Unidos. Rio de Janeiro: Presença.

Silva, Fernando Teixeira da. (2013a). Entre o acordo e o acórdão: a Justiça do Trabalho paulista na antevéspera do Golpe de I964. In: Gomes, Angela de Castro \& Silva, Fernando Teixeira da (orgs.). A Justiça do Trabalho e sua história: direitos dos trabalhadores no Brasil. Campinas: Ed. Unicamp, p. 203-26I.

Silva, Fernando Teixeira da. (2013b). Poder, normas e justiça: os trabalhadores e o Tribunal Regional de São Paulo (I963I964). Tese de Livre-Docência. Campinas, IFCH-Unicamp.

Silva, Fernando Teixeira da. (2010). The Brazilian and Italian Labor Courts: Comparative notes. International Review of Social History, 55, p. 38I-4I 2.

Véras, Roberto \& Ladosky, Mário. (20I4). O "novo sindicalismo" pela ótica dos estudos do trabalho. Mundos do Trabalho, 6/I I, p. I47-I70.

Welch, Cliff. (1995). Labor internationalism: U. S. involvement in Brazilian Unions, I945-I965. Latin American Research Review, 30/2, p. 62-89. 


\section{CORPORATIVISMO E REGULAMENTAÇÃO DO TRABALHO NO BRASIL: UM DEBATE ENTRE ESPECIALISTAS BRASILEIROS E NORTE-AMERICANOS NA DÉCADA DE 1960}

Resumo

De acordo com os sindicalistas e especialistas do trabalho norte-americanos, o corporativismo brasileiro representava um grande empecilho para o desenvolvimento das relações laborais no Brasil. Nesse sentido, este artigo busca compreender como os sindicalistas norte-americanos construíram uma noção bastante crítica do corporativismo brasileiro, ao longo da década de ig6o. Para tanto, a análise sobre a atuação da AFL-CIO no Brasil, considerada a maior central sindical norte-americana, mostra-se fundamental. De outro lado, o artigo analisa a visão de importantes juristas e especialistas brasileiros de destaque na área do direito trabalhista e suas ideias sobre o funcionamento do corporativismo brasileiro. Por fim, o artigo apresenta as características principais dos modelos corporativista e contratualista, conforme as interpretações de dois importantes advogados trabalhistas norte-americanos.

\section{THE BRAZILIAN CORPORATIST INDUSTRIAL REGULATION SYSTEM UNDER DISCUSSION BY BRAZILIAN AND U. S. SPECIALISTS (1960)}

Abstract

Accordingly to the U. S. specialists and trade unionists, the Brazilian corporatist labor system was seen as a major obstacle to the development of the industrial relations in Brazil. This article aims to understand how the U. S. specialists in the rg6os critically portrayed the Brazilian corporatist as an inappropriate system. In order to understand the U. S. view, this study is based on the role of the AFL-CIO played in Brazil. Besides, this study analyzes the ideas of Brazilian labor specialists about the corporatism running in Brazil before the I 964 coup. Finally, this article presents the main features of the U. S. contractualism and Brazilian corporatism, according to the analysis of two U.S. labor lawyers. In this sense, this study aims to contribute to the scholarship that has challenged the monolithic understanding of the Brazilian corporatism.
Palavras-chave

Sindicalismo;

Corporativismo;

Contratualismo;

AFL-CIO;

Ditadura.

Keywords

Trade Unionism;

Corporatist Industrial Regulation;

Contractualism;

AFL-CIO;

Dictatorship. 